\title{
INFLUENCE OF DIFFERENT KIND OF CLOTHING MATERIAL ON SELECTED CARDIOVASCULAR, RESPIRATORY AND PSYCHOMOTOR PARAMETERS DURING MODERATE PHYSICAL EXERCISE
}

\author{
IZABELA CIESIELSKA ${ }^{1}$, MAREK MOKWIŃSKI ${ }^{2}$, and MONIKA ORŁOWSKA-MAJDAK ${ }^{3}$ \\ ${ }^{1}$ Technical University of Łódź \\ Institute of Architecture of Textiles \\ ${ }^{2}$ Medical University of Łódź \\ Department of Cell-to-Cell Communication, Chair of Experimental and Clinical Physiology \\ ${ }^{3}$ Medical University of Łódź \\ Department of Experimental Physiology, Chair of Experimental and Clinical Physiology
}

\begin{abstract}
Objectives: The aim of the experiment was to analyze the influence that the clothing material may have on human physiology and thermal comfort both at rest and physical effort to answer the question which fabric is better, a natural or a synthetic one. Materials and Methods: We measured some psychomotor parameters: critical flicker frequency (CFF), reaction time to auditory/visual stimuli (RT), concentration of attention (CA); cardiovascular parameters: blood pressure (BP), heart rate $(\mathrm{HR})$ and respiratory parameters: tidal volume $\left(\mathrm{V}_{\mathrm{T}}\right)$, minute ventilation $\left(\mathrm{V}_{\mathrm{E}}\right)$, oxygen consumption $\left(\mathrm{V}_{\mathrm{O} 2}\right)$, carbon dioxide output $\left(\mathrm{V}_{\mathrm{CO}_{2}}\right)$, respiratory exchange ratio (RER) in human volunteers before, during and after physical effort. The subjects performed a 15 -min treadmill test on treadmill wearing clothes made of two different materials: $100 \%$ coarse wool and $100 \%$ acrylic. An interview was conducted directly before the exercise test to assess the subjects' general mood and wellbeing on that day. Besides, before and after the test, the subjects in their own words described the sensation they felt with respect to the physiological comfort of particular clothing. Results: The results showed that wearing clothes made of different fabrics had some influence on the cardiovascular and respiratory parameters during physical effort but it did not have any effect on the psychomotor skills. The perception of physiological comfort by the subjects wearing coarse wool or acrylic depended on their physiological state and differed at rest and after the physical effort. Conclusions: The course of physiological processes depends on the kind of clothing a given person is wearing. It is not possible to clearly define which of the two clothing materials: natural - wool, or synthetic - acrylic is better. Each of them exerts a different effect on the human organism. The usefulness of a given type of clothing material seems to depend on the human physiological state and the related thermoregulatory processes.
\end{abstract}

Key words:

Physical Effort, Wool Set of Garment, Acrylic Set of Garment, Psychomotor Parameters, Cardiovascular Parameters, Respiratory Parameters

\section{INTRODUCTION}

The kind of clothing and the material it is made of may determine the overall comfort of an individual wearing it [1-4] and have impact on his/her everyday activities. The clothing material may also have influence on the results achieved in professional athletics, as well as on the efficiency in non-sportive activities. There are also special standards for professional uniforms of firefighters, policemen, soldiers, and all people working under difficult external conditions. Those standards concern the thermal, 
physiological and ergonomic comfort of the users and the finishing of the uniforms. The uniforms must comply with the European Norm with respect to the ergonomic comfort, protection, fire resistance, thermal resistance, air permeability, moisture evaporation, etc. [5].

Most of the studies addressing this problem focus on the improvement of textile structure and finishing technologies. Non-durable and semi-durable flame retardants, based mostly on phosphate or phosphonate salts, continue to be used in infrequently washed or disposable clothing. Recent improvements aim at imparting better wash resistance [6]. In some studies, extreme external working conditions are simulated in order to analyze the physiological comfort of wearing uniforms. Human trials are the commonly used methods to evaluate the physiological impact of clothing on human physiology. Treadmill exercise test in a climatic chamber is usually performed to validate the results obtained using small-scale test methods or manikins [3].

The research concerning the effect that the clothing material may have on the physiological parameters in humans was undertaken by a few research centers worldwide. One study compared the influence of clothing made of natural raw materials, like linen and cotton, with those made of synthetic materials like polyester, polyamide, and polypropylene [7]. It was generally focused on the thermoregulation in humans wearing different kinds of clothes. The use of clothing represents an insulation layer and as such imposes a barrier against heat transfer and evaporation from the skin surface. The influence of the kind of clothing material is especially seen during the physical effort when increased muscular activity results in increased heat production, affecting the temperature balance in the body [7]. There are literature reports supporting the effect of the clothing fabric on thermoregulation in exercising humans [8]. However, there are also reports in which no difference was found in relation to the clothing material [9]. Very few studies concerned the measurements of skin temperature, body temperature, rectal temperature [10], heart rate [11], systolic and diastolic blood pressure $\mathrm{BP}$ [1], oxygen consumption $\left(\mathrm{V}_{\mathrm{O} 2}\right)$ [10], skeletal muscles' activity [12], reaction time [13], determination of the antioxidant activity of plasma and the level of immunoglobulin A [14] in humans wearing clothes made of different raw materials.

The present study compares the influence of $100 \%$ coarse wool and $100 \%$ acrylic sets of clothing on selected psychomotor, cardiovascular and respiratory parameters during submaximal physical effort. The following parameters were examined to evaluate the psychomotor skills: critical flicker frequency (CFF), reaction time to auditory/visual stimuli (RT) and concentration of attention (CA). We have decided to choose these parameters for the study as in our opinion they are most susceptible to the changes evoked by physical effort.

The CFF threshold is defined as the frequency at which a flickering light cannot be distinguished from a steady, non-flickering light. People can see lights flashing on and off for up to about 50 flashes per second $(50 \mathrm{~Hz})$. CFF is useful for assessing the temporal characteristics of the visual system and visual perception [15]. Additionally, CFF thresholds correlate with various parameters of intelligence, and have been regarded by clinicians as a general measure of the cortical processing capacity. For these reasons, CFF is used as a cognitive indicator in drug studies, as a measure of fatigue, and has been suggested as a diagnostic measure for various brain diseases [16].

$\mathrm{RT}$ is defined as "the interval between the onset of the stimulus and the response under the condition that the subject has been instructed to respond as rapidly as possible" [17]. RT measurements have been employed in medicine and psychology and the measuring techniques have been continuously improved [18].

Attention is one of the components of consciousness [19]. It was regarded as a principle of psychology by James in 1890. Moskovitch, in 1979, defined attention as "a control process that enables the individual to select from a number of alternatives the task he will perform or the stimulus he will process and the cognitive strategy he will adopt to carry out these operations" [19]. Attention Deficit Hyperactivity Disorder (ADHD) is presently one of the most frequently diagnosed disorders in children, and has recently been also recognized in adults [20]. 


\section{MATERIALS AND METHODS}

Twenty young healthy volunteers, students of the Medical University of Łódź and the Technical University of Łódź (6 females and 14 males, aged 21-29 years), were eligible for the study. The subjects had been informed about the purpose of the project, the study design and procedures and they signed consent to participate in the study. They were asked to perform a 15 -min treadmill exercise test twice. At first, the subjects were wearing a $100 \%$ coarse wool clothing set. Then they changed into the clothes made of $100 \%$ acrylic. All the tests were performed at room temperature of $17-23^{\circ} \mathrm{C}$ (mean $19.8^{\circ} \mathrm{C}$ and $19.7^{\circ} \mathrm{C}$ for the stages of wearing woolen (I) and acrylic clothing (II), respectively) with relative humidity of $28-45 \%$ (mean $31.1 \%$ and $30.9 \%$ for stage I and II, respectively), and atmospheric pressure of $977-1000 \mathrm{hPa}$ (mean $989 \mathrm{hPa}$ and $989.9 \mathrm{hPa}$ for stage I and II, respectively). Selected physiological parameters were measured before, during and after the physical exercise. The studies also comprised an interview: each subject was to assess his/her general mood and wellbeing before the treadmill test, choosing from a 15-item scale of response categories.

\section{Clothing description}

Both the sets of clothing tested during the study were designed and made at the Institute of Architecture of Textiles, Technical University of Łódź, Poland. Each set consisted of a long-sleeved pullover and trousers. One set was made of $100 \%$ coarse-wool knitted fabric, and the other of $100 \%$ acrylic-knitted fabric. The wale stitch density was 36-columnes $/ 1 \mathrm{dm}$ and the course stitch density 54 rows $/ 1 \mathrm{dm}$ in both the fabrics. The air permeability for both sets was similar and approximated $1500 \mathrm{dm}^{3} / \mathrm{m}^{2} \times$ s.

\section{Exercise description}

A 15-min exercise test was performed on the Trackmaster treadmill with a programmed speed according to modified Bruce protocol. The speed was gradually increasing: from $3 \mathrm{~km} / \mathrm{h}$ in the first minute of testing, through $4 \mathrm{~km} / \mathrm{h}$ during the next $4 \mathrm{~min}$ and $5 \mathrm{~km} / \mathrm{h}$ during another $5 \mathrm{~min}$ to $6 \mathrm{~km} / \mathrm{h}$ during the last $5 \mathrm{~min}$ of testing.
The treadmill was lifted to an altitude of 10 degrees to the base.

The physical effort of the whole study group corresponded to $55-60 \%$ of the maximal volume of oxygen consumption $\mathrm{VO}_{2 \max }$.

\section{Physiological parameters}

Cardiovascular and respiratory parameters

Arterial blood pressure (BP) and heart rate (HR) were measured before and after the treadmill exercise test using electronic sphygmomanometer OMRON M4-I. Moreover, some respiratory parameters and HR were monitored during the test using VO2000 MedGraphics Cardiorespiratory Diagnostic Systems that was compatible with Breeze suite 6.2A MedGraphics software. The subject examined was connected to the measuring system by the preVent ${ }^{\mathrm{TM}}$ mask attached to the pneumotach and umbilical clip. Data regarding respiratory rate $(\mathrm{RR} / \mathrm{min})$, gas exchange coefficient (RER), carbon dioxide exhalation $\left(\mathrm{V}_{\mathrm{CO} 2} \mathrm{ml} / \mathrm{min}\right)$, oxygen inhalation $\left(\mathrm{V}_{\mathrm{O} 2} \mathrm{ml} / \mathrm{min}\right)$, tidal volume $\left(\mathrm{V}_{\mathrm{T}} \mathrm{BTPS} \mathrm{ml}\right)$, and minute ventilation $\left(\mathrm{V}_{\mathrm{E}} \mathrm{BTPS} \mathrm{l} / \mathrm{min}\right)$ were saved on PC.

Psychomotor skills

Critical flicker frequency (CFF) was measured using the device constructed at the Nofer Institute of Occupational Medicine, Łódź, Poland. The subject examined was instructed to observe a flickering light. The flickering increased within the range of $20-60 \mathrm{~Hz}$ and the subject was asked to signal the moment at which he/she could not distinguish the flickering light from a constant light. The digital indicator on the device showed the CFF threshold at which the subject did not recognize a single flash any more.

Reaction time (RT) was measured using the MRK-432 device produced in Szczecin, Poland. This device generated light stimuli of red, green and white colour alternately with low- and high-level sound stimuli. The subject was supposed to react to the red light with the right hand and to the low-level sound with the left hand as soon as possible. The total number of programmed stimuli was 19. 
Concentration of attention (CA) was measured using cross apparatus K-6 produced in Szczecin, Poland. The device had a front panel with buttons arranged in 7 rows and 7 columns of which the upper left and the top row were lamps. The program randomly switched on two lamps at the same time, one in a column and one in a row. The subject was supposed to press the appropriate button which was at the intersection of the straight lines between the two lamps. The measuring device counted the number of correct responses per 49 light stimuli released. The speed of the popping lights was 50 changes per min.

\section{Wellbeing questionnaire}

The questionnaire concerned the subject's perception of his/her general mood and wellbeing before the physical exercise, assessed on a 15-item scale of response categories. It was based on the Positive and Negative Affect Scale (PANAS). The following response categories made up the scale:

1. I feel very bad because I am very anxious.

2. I feel very bad because I am strongly depressed.

3. I feel bad because I am anxious.

4. I feel bad because I am depressed.

5. I feel rather bad.

6. I feel rather bad because I am slightly anxious.

7. I feel neutral, neither well nor bad.

8. I feel quite well as I am slightly excited.

9. I feel quite well as I am quite satisfied.

10. I feel quite well as I generally have that kind of mood.

11. I feel well because I am in a good mood.

12. I feel well because I have a hope for a change for better.

13. I feel well because I am positively excited.

14. I feel very well because I am relaxed.

15. I feel very well because I am fully satisfied.

The subjects responded to the questionnaire directly before the treadmill test. Besides, before and after the test, the subjects were asked to describe in their own words the physiological comfort of the two different kinds of clothing they were wearing for the study.

\section{Course of experiment}

The experiment started with an interview to assess the subjects' general mood and wellbeing on the day of the testing. Then the subjects put on a $100 \%$ coarse wool set of clothing and became acclimatized to the room temperature for 30 minutes. Meanwhile, they were acquainted with the measuring devices and took part in a few preliminary psychomotor tests. At the end of the acclimatization period, the subjects were asked to characterize the physiological comfort of the clothing worn during the test. Then, arterial blood pressure (SBP 1/ DBP 1) and heart rate (HR 1) were measured using electronic sphygmomanometer OMRON M4-I. This was followed by the CFF, RT and CA tests. Directly after that, the subject stepped on the treadmill, put on the facial mask for monitoring respiratory parameters, and fixed the HR detector on his/her chest. The subject started walking on the treadmill at a programmed speed that was gradually increased. The following parameters were monitored during the physical effort: HR, RR, RER, $\mathrm{V}_{\mathrm{CO} 2}, \mathrm{~V}_{\mathrm{O} 2}, \mathrm{~V}_{\mathrm{T}}$ BTPS and $\mathrm{V}_{\mathrm{E}}$ BTPS. In the first minute after the test, arterial blood pressure (SBP 2/DBP 2) and heart rate (HR 2) were measured and the psychomotor parameters (CFF, RT, and CA) were assessed. After a 7.5-min interval, blood pressure (SBP 3/DBP 3) and heart rate (HR 3) were measured again, and the measuring procedure was repeated once more after another $2.5 \mathrm{~min}(10 \mathrm{~min}$ after termination of treadmill test) for blood pressure (SBP 4/DBP 4) and heart rate (HR 4).

When the treadmill test was over, the subject described in his/her own words the sensation he/she had felt with respect to the physiological comfort of the coarse wool set of clothing.

After this series of measurements, the subjects rested for at least $30 \mathrm{~min}$, wearing their own clothes. Then they changed into the acrylic clothing set. The acclimatization in the new clothing lasted $30 \mathrm{~min}$. The whole measuring procedure was repeated using the same time intervals between single measurements. The results concerning the resting state of the subjects were compared with those obtained after the exercise test. 


\section{Ethics}

The study design was approved by the Biomedical Ethics Committee of the Medical University of Łódź, Poland, RNN/299/06/KB.

\section{Statistics}

Statistical analysis was carried out using Statistica software. The Shapiro-Wilk test confirmed the normality of data distribution. Student-t test was used for the dependent variables to check whether the testing results before the physical effort differed significantly in relation to the type of the clothing material tested. This test was also used to compare HR and respiratory parameters at different time-points of the treadmill exercise test in the subjects wearing the two clothing sets. Data obtained from all the measurements performed during the treadmill test were divided according to the four time intervals of the testing that corresponded to the increasing intensity of physical effort. The first set of data referred to the measurements carried out within the 1st min of testing, the second one after $5 \mathrm{~min}$, the third one after $10 \mathrm{~min}$ and the fourth one after $15 \mathrm{~min}$ of the treadmill test. Respective data for the subjects wearing coarse wool and acrylic clothing were compared. They were analyzed with the Shapiro-Wilk test which did not confirm the normality of their distribution. Mann-Whitney U test, ANOVA Friedman, and Schéffe test post hoc were employed to compare respiratory parameters and HR during the test in the subjects wearing the two clothing sets. The level of statistical significance for all tests was $p<0.05$.

\section{RESULTS}

\section{Influence of clothing material \\ on psychomotor parameters}

The authors compared psychomotor parameters before and after the treadmill test in both the clothing sets. CFF was the only psychomotor parameter that has changed significantly $(\mathrm{p}<0.05)$, compared to the initial value, while the subjects were wearing woolen clothes: it was found to increase from $35.86 \pm 0.68 \mathrm{~Hz}$ to $37.19 \pm 0.66 \mathrm{~Hz}$ (Table 1). No statistically significant differences in CFF values were noted during the stage when the subjects had acrylic clothes on. We presume that the submaximal physical effort may affect the visual perception of an individual but the level of changes may depend on the kind of clothing he/she is wearing during the effort. Moreover, we did not observe any statistically significant differences in CA and RT parameters in relation to the kind of clothing worn.

\section{Influence of clothing material on cardiovascular parameters before and after physical effort}

The values of SBP, DBP, and HR before and after the exercise test were compared in relation to the kind of clothing worn by the subjects (Table 2). It was found that during the acclimatization period in each set of clothes, the BP and HR values differed significantly $(\mathrm{p}<0.05)$. Wearing the woolen clothes significantly increased the systolic BP $(133.95 \pm 14.39 \mathrm{mmHg})$ compared to wearing the acrylic clothes $(126.20 \pm 13.87 \mathrm{mmHg})$. In the group wearing woolen clothing, HR decreased significantly $(81.45 \pm 11.20)$ as compared with respective

Table 1. Psychomotor parameters in subjects wearing 100\% coarse wool and $100 \%$ acrylic clothing (mean \pm SE)

\begin{tabular}{lcccc}
\hline \multirow{2}{*}{\multicolumn{1}{c}{ Study parameter }} & \multicolumn{2}{c}{ Coarse wool clothing } & \multicolumn{2}{c}{ Acrylic clothing } \\
\cline { 2 - 5 } & $\begin{array}{c}\text { Before } \\
\text { physical effort (B) }\end{array}$ & $\begin{array}{c}\text { After } \\
\text { physical effort (A) }\end{array}$ & $\begin{array}{c}\text { Before } \\
\text { physical effort (B) }\end{array}$ & $\begin{array}{c}\text { After } \\
\text { physical effort (A) }\end{array}$ \\
\hline Critical flicker frequency $(\mathrm{Hz})$ & $35.86 \pm 0.68^{*}$ & $37.19 \pm 0.66^{*}$ & $36.93 \pm 0.71$ & $37.91 \pm 0.71$ \\
Reaction time (ms) & $343.40 \pm 8.24$ & $341.81 \pm 8.23$ & $340.30 \pm 11.30$ & $341.59 \pm 10.49$ \\
Concentration of attention & $38.30 \pm 1.80$ & $38.65 \pm 1.90$ & $38.70 \pm 1.60$ & $38.25 \pm 1.81$ \\
(number of correct answers) & & & & \\
\hline
\end{tabular}

* Statistically significant difference as revealed by Student-t test for paired variables (A v. B). Other comparisons did not show any difference in relation to the kind of clothing material. 
Table 2. Systolic (SBP) and diastolic (DBP) blood pressure and heart rate (HR) recorded before treadmill exercise test and at different time-points after the test in subjects wearing different sets of clothing (mean $\pm \mathrm{SE}$ )

\begin{tabular}{|c|c|c|c|}
\hline Results & Study parameter & Coarse wool clothing (W) & Acrylic clothing (A) \\
\hline \multirow[t]{3}{*}{ Before physical effort } & SBP1 & $133.95 \pm 3.21^{*}$ & $126.20 \pm 3.10^{*}$ \\
\hline & DBP1 & $81.95 \pm 1.69$ & $77.60 \pm 2.19$ \\
\hline & HR1 & $81.45 \pm 2.50^{*}$ & $88.75 \pm 2.77^{*}$ \\
\hline \multicolumn{4}{|l|}{ After physical effort (min) } \\
\hline \multirow[t]{3}{*}{1} & SBP2 & $157.95 \pm 3.10^{*}$ & $148.15 \pm 3.22 *$ \\
\hline & DBP2 & $89.84 \pm 2.21$ & $86.45 \pm 2.65$ \\
\hline & HR2 & $127.05 \pm 3.34$ & $122.65 \pm 3.92$ \\
\hline \multirow[t]{3}{*}{7.5} & SBP3 & $135.70 \pm 3.28$ & $131.78 \pm 2.81$ \\
\hline & DBP3 & $87.40 \pm 1.86$ & $84.47 \pm 2.24$ \\
\hline & HR3 & $104.95 \pm 2.50$ & $105.42 \pm 3.28$ \\
\hline \multirow[t]{3}{*}{10} & SBP4 & $130.94 \pm 3.45$ & $126.05 \pm 2.03$ \\
\hline & DBP4 & $87.05 \pm 2.04$ & $82.58 \pm 2.20$ \\
\hline & HR4 & $103.00 \pm 1.94$ & $102.35 \pm 2.48$ \\
\hline $\begin{array}{l}\text { Level of significance as estimated by Student-t test } \\
\text { for paired variables when comparing the results } \\
\text { recorded before the exercise test and at different } \\
\text { time-points after the effort. The lack of difference } \\
\text { is an evidence of the parameter's regaining its } \\
\text { inital value }\end{array}$ & $\begin{array}{l}\text { SBP1 v. SBP2 } \\
\text { DBP1 v. DBP2 } \\
\text { HR1 v. HR2 } \\
\text { SBP1 v. SBP3 } \\
\text { DBP1 v. DBP3 } \\
\text { HR1 v. HR3 } \\
\text { SBP1 v. SBP4 } \\
\text { DBP1 v. DBP4 } \\
\text { HR1 v. HR4 }\end{array}$ & $\begin{array}{c}\mathrm{P}<0.05 \\
\mathrm{P}<0.05 \\
\mathrm{P}<0.05 \\
\quad \mathrm{NS} \\
\mathrm{P}<0.05 \\
\mathrm{P}<0.05 \\
\quad \mathrm{NS} \\
\mathrm{P}<0.05 \\
\mathrm{P}<0.05\end{array}$ & $\begin{array}{l}\mathrm{P}<0.05 \\
\mathrm{P}<0.05 \\
\mathrm{P}<0.05 \\
\mathrm{P}<0.05 \\
\mathrm{P}<0.05 \\
\mathrm{P}<0.05 \\
\quad \mathrm{NS} \\
\mathrm{P}<0.05 \\
\mathrm{P}<0.05\end{array}$ \\
\hline
\end{tabular}

* Statistically significant difference as revealed by Student-t test for paired variables (A v. W). No other comparison showed any difference in relation to the kind of clothing material.

NS - not significant.

values among subjects wearing acrylic $(88.75 \pm 12.41)$. The systolic BP in the subjects wearing woolen clothes $(157.95 \pm 13.87 \mathrm{mmHg})$ was significantly higher than in the group wearing acrylic clothing $(148.15 \pm 14.42 \mathrm{mmHg})$ within the first minute after the treadmill test.

Cardiovascular parameters recorded before the onset of the experiment were compared with those collected $1 \mathrm{~min}, 7.5 \mathrm{~min}$, and $10 \mathrm{~min}$ after the physical effort at both stages of the experiment. The aim of this comparison was to find out whether the kind of clothing may have influence on the recovery time after the physical effort (Table 2). Systolic BP regained its initial values earlier in the subjects wearing wool - within $7.5 \mathrm{~min}$ (SBP1 vs. SBP3, $\mathrm{p}=\mathrm{NS}$ ) than in those wearing acrylic - within $10 \mathrm{~min}$ (SBP1 vs. SBP4, p = NS) after the treadmill test. As for the diastolic BP and HR, the values of these parameters after the effort remained higher than their initial levels, regardless of the type of clothing $(p<0.05)$.

\section{Influence of clothing material on respiratory parameters and $\mathrm{HR}$ values during physical effort}

The Mann-Whitney U test was employed to compare the findings for respiratory parameters and HR during the four time intervals of the exercise test in the subjects wearing both sets of clothing. It is worth noting that from 5th min to 15th min of testing, the RER coefficient reached higher values in the subjects wearing wool than in those wearing acrylic (Fig. 1A). However, a statistically significant difference $(p<0.05)$ could be 
Table 3. Selected respiratory parameters during treadmill exercise test at the time intervals of $0-1$ st min, 2nd-5th min, 6th-10th min, and 11th-15th min in subjects wearing $100 \%$ coarse wool and 100\% acrylic clothing (mean \pm SE)

\begin{tabular}{llllllc}
\hline \multirow{2}{*}{$\begin{array}{c}\text { Duration of physical } \\
\text { effort (min) }\end{array}$} & \multicolumn{2}{c}{ RER } & \multicolumn{2}{c}{$\mathrm{V}_{\mathrm{C} 22} 1 / \min$} & \multicolumn{2}{c}{$\mathrm{V}_{\text {O2 }} 1 / \min$} \\
\cline { 2 - 7 } & $\mathrm{W}$ & $\mathrm{A}$ & $\mathrm{W}$ & $\mathrm{A}$ & $\mathrm{W}$ & $\mathrm{A}$ \\
\hline 1 & $0.98 \pm 0.09$ & $1.00 \pm 0.07$ & $0.49 \pm 0.14$ & $0.32 \pm 0.05$ & $0.42 \pm 0.07$ & $0.32 \pm 0.04$ \\
5 & $1.01 \pm 0.08^{*}$ & $0.84 \pm 0.02^{*}$ & $1.69 \pm 0.15^{*}$ & $1.35 \pm 0.11^{*}$ & $1.68 \pm 0.95$ & $1.56 \pm 0.10$ \\
10 & $1.11 \pm 0.07^{*}$ & $1.00 \pm 0.01^{*}$ & $2.13 \pm 0.19$ & $1.88 \pm 0.11$ & $1.91 \pm 0.11$ & $1.88 \pm 0.10$ \\
15 & $1.18 \pm 0.07$ & $1.09 \pm 0.02$ & $2.79 \pm 0.17$ & $2.70 \pm 0.14$ & $2.41 \pm 0.14$ & $2.46 \pm 0.13$ \\
\hline
\end{tabular}

* Statistically significant difference (A v. W) as revealed by Mann-Whitney U test. It refers to the values recorded in subjects wearing $100 \%$ coarse wool clothes (W) compared to those wearing $100 \%$ acrylic clothes (A).
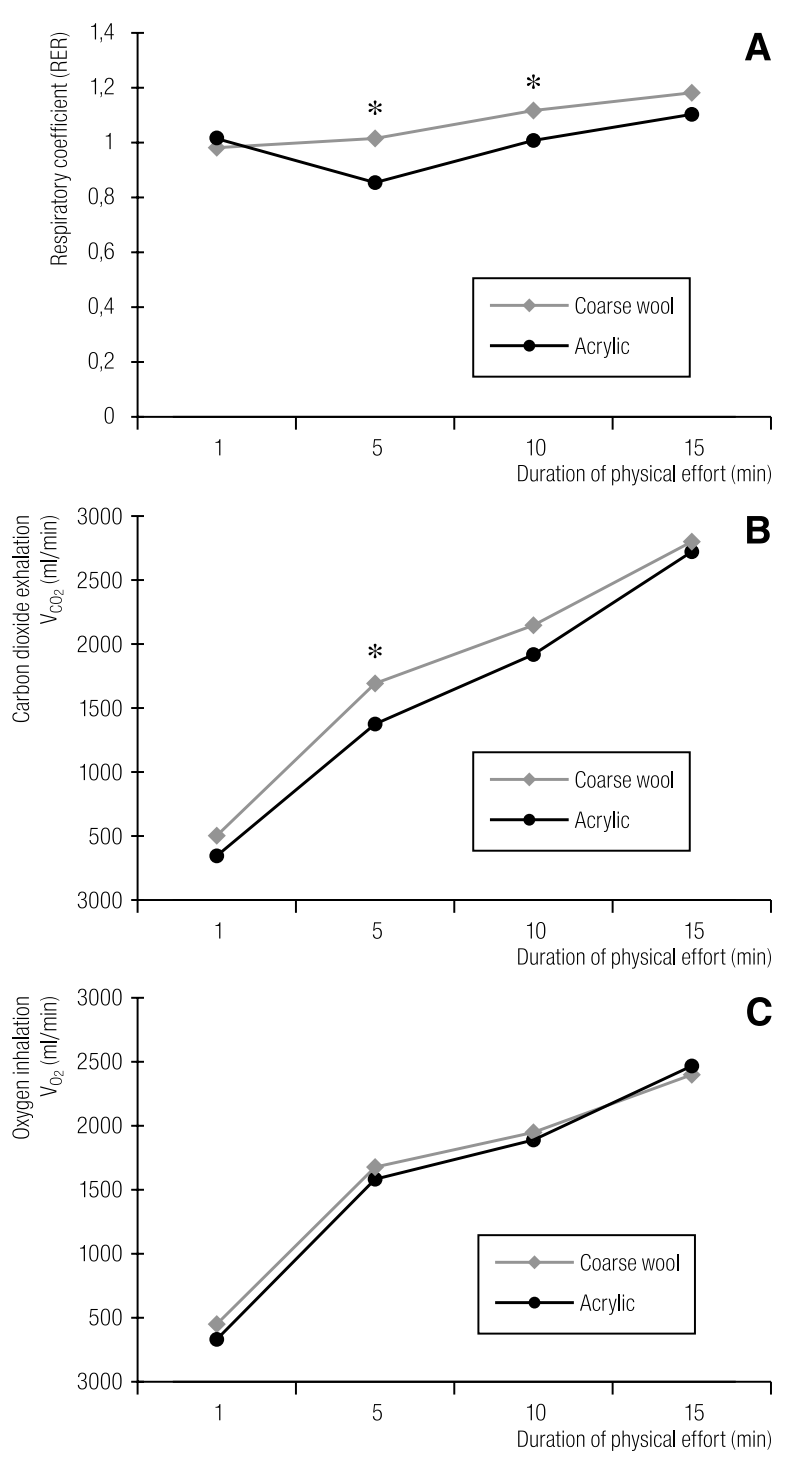

*Statistically significant difference between the values for coarse wool and acrylic

Fig. 1. Gas exchange parameters at 1st, 5th, 10th and 15th min of treadmill exercise test in subjects wearing coarse wool or acrylic clothes: (A) respiratory coefficient (RER), (B) carbon dioxide exhalation $\left(\mathrm{V}_{\mathrm{CO} 2}\right)$, and $(\mathrm{C})$ oxygen inhalation $\left(\mathrm{V}_{\mathrm{O} 2}\right)$. observed only after the 5 th and 10th min of physical effort. The volume of $\mathrm{CO}_{2}$ exhalation $\left(\mathrm{V}_{\mathrm{CO} 2}\right)$ was higher in the subjects dressed in woolen clothes after 5th, 10th, and 15th min of testing (Fig. 1B). However, the highest statistically significant difference was noted after the 5 th min. The difference in minute $\mathrm{O}_{2}$ consumption in the subjects wearing both the types of clothes was not significant $(\mathrm{p}>0.05)$ (Fig. 1C). Moreover, the total $\mathrm{O}_{2}$ consumption during the testing in woolen and acrylic clothing was estimated based on curve plotting and the difference was not significant either $(p>0.05)$. The values of RER, $\mathrm{V}_{\mathrm{CO} 2}$ and $\mathrm{V}_{\mathrm{O} 2}$ are shown in Table 3 .

All the other study parameters, namely RR, $\mathrm{V}_{\mathrm{T}} \mathrm{BTPS}$, $\mathrm{V}_{\mathrm{E}} \mathrm{BTPS}$, and HR showed similar values at both the stages of the experiment at all the time intervals of the treadmill test. They are shown in Figs. 2A, B, C, and D. A large difference in $\mathrm{RR}$ values within the first minute of testing was noted between the subjects wearing wool $(17.42 \pm 1.67)$ and acrylic $(23.55 \pm 3.45)$. The difference is remarkable but was found to be of no statistical significance (Fig. 2A).

The comparison of changes in selected respiratory parameters and HR during the physical effort shows that these values were continuously increasing during the test both in the subjects wearing woolen and acrylic clothes. However, in those performing the test in acrylic clothes, RER decreased after 5 th min, to rapidly grow after the 15 th $\mathrm{min}$. Also, the RR value in the subjects in acrylic clothes increased significantly only towards the end of the programmed effort, which was approximately at the 15 th $\mathrm{min}$ of testing. 

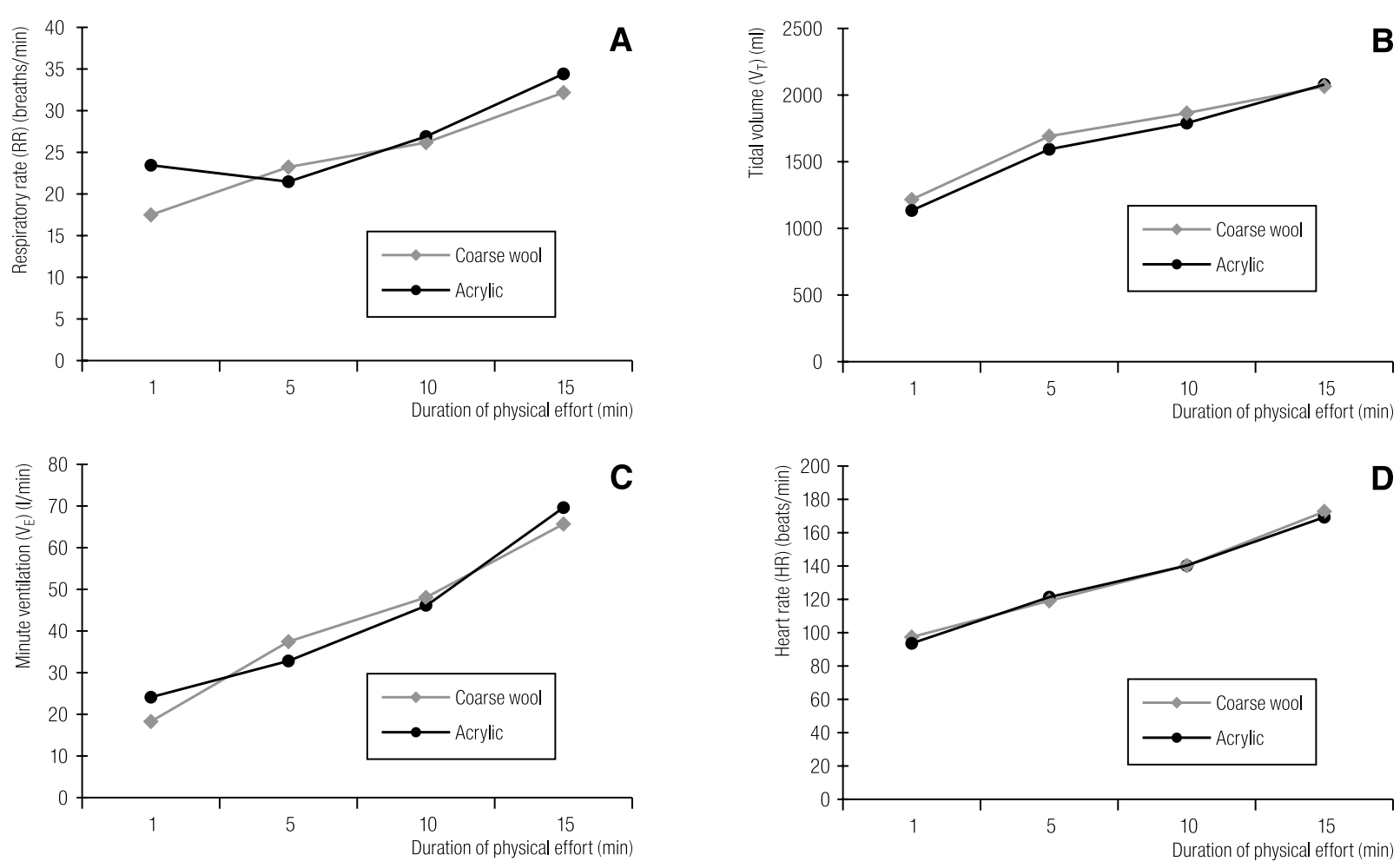

Fig. 2. Respiratory parameters and heart rate at 1st, 5th, 10th and 15th min of treadmill exercise test in subjects wearing coarse wool or acrylic clothes: $(A)$ respiratory rate $(R R),(B)$ tidal volume $\left(V_{T}\right),(C)$ minute ventilation $\left(V_{E}\right)$, and $(D)$ heart rate $(H R)$.

Table 4. Responses to questionnaire regarding the subjects' general mood and wellbeing

\begin{tabular}{lc}
\hline \multicolumn{1}{c}{ Mood description } & Number of responses \\
\hline 1. I feel very bad because I am very anxious & 0 \\
2. I feel very bad because I am strongly depressed & 0 \\
3. I feel bad because I am anxious & 0 \\
4. I feel bad because I am depressed & 0 \\
5. I feel rather bad & 0 \\
6. I feel rather bad because I am slightly anxious & 6 \\
7. I feel neutral, neither well nor bad & 6 \\
8. I feel quite well as I am slightly excited & 1 \\
9. I feel quite well as I am quite satisfied & 2 \\
10. I feel quite well as I generally have that kind of mood & 0 \\
11. I feel well because I am in a good mood & 8 \\
12. I feel well because I have a hope for a change for better & 0 \\
13. I feel well because I am positively excited & 0 \\
14. I feel very well because I am relaxed & 0 \\
15. I feel very well because I am fully satisfied & 2 \\
\hline
\end{tabular}




\section{Assessment of the subjects' wellbeing before the experiment}

The present study involved an evaluation of the subjective perception of physiological comfort in relation to the type of clothing worn during the treadmill test. Therefore, an interview was conducted directly before the experiment to assess the subjects' general mood and wellbeing on that particular day. This was done to eliminate the potential bias related to the effect that a negative attitude could have had on the findings of the experiment. The interview revealed that the subjects did not feel any major discomfort that could have affected the evaluation. The findings of the interview are shown in Table 4.

\section{DISCUSSION}

Before the onset of the experiment, all the subjects shared an opinion that the coarse wool set of clothing was extremely unpleasant in contact with the skin, and they felt discomfort when wearing it. They reported an opposite sensation with respect to the acrylic set. However, their impression changed after the physical effort: they were sweating and felt discomfort in the acrylic set of garments, while felt comfortably in woolen clothes. This may have been due to the difference in the yarn and fiber structure of the two materials. The textiles made of acrylic have a lower air and liquid permeability than the woolen textiles. This may be the reason for the differences in physiological parameters observed during the physical effort performed when wearing the two kind of clothing.

The highest differences could be noted with respect to respiratory parameters, such as the mean value and distribution of RER coefficient and the mean volume of exhaled $\mathrm{CO}_{2}\left(\mathrm{~V}_{\mathrm{CO} 2}\right)$. The values of those parameters increased with the increasing level of physical effort and the time of testing in the subjects wearing both the sets of clothes. However, in the subjects wearing wool, RER and $\mathrm{V}_{\mathrm{CO} 2}$ were higher than in those wearing acrylic. The respiratory exchange ratio (RER) is known to increase during the physical exercise due to the hyperventilation and enhanced $\mathrm{CO}_{2}$ excretion. In the case of intensive effort, when the lactate threshold is exceeded, $\mathrm{CO}_{2}$ is overproduced due to anaerobic metabolism of glucose resulting in lactic acid production. This may refer to our experiment as the subjects have been recruited from among students who are not used to exercise and usually lead a sedentary lifestyle. In the population who does not practice physical exercise regularly, the anaerobic threshold (AT) occurs at a lower level than in sportsmen. In the students at the University of Physical Education, the AT level was reached at the point of a $60 \%$ maximum oxygen consumption $\left(\mathrm{VO}_{2 \max }\right)$ [21], and the first-minute changes in lactic acid concentration in blood could be observed after the physical effort of intensity exceeding $40 \% \mathrm{VO}_{2 \max }[22]$. In our study, the intensity of physical effort was at the level of $55-60 \% \mathrm{VO}_{2 \max }$.

The fact that higher levels of RER and $\mathrm{V}_{\mathrm{CO} 2}$ could be noted among subjects performing the test in $100 \%$ coarse wool clothing provides evidence that at the same level of physical effort, the human organism reacts in a different way depending on the type of the clothing material, and the type of fibre in particular. The findings regarding RER and $\mathrm{V}_{\mathrm{CO} 2}$ values indicate that performing exercise in $100 \%$ coarse wool set of clothing seems to be a higher physical effort to the system than does the performance in acrylic clothes.

The other respiratory parameters $\left(\mathrm{RR}, \mathrm{V}_{\mathrm{t}}, \mathrm{VE}\right)$ also increased during the exercise, but no statistically significant differences depending on the type of fabric could be observed. A more remarkable increase in RR and VE values during the exercise was found in the subjects wearing wool (1.8x and $3.5 \times$, respectively) than in those wearing acrylic (1.4x and $2.9 \times$, respectively). At the same time, it can be noted that the increase in the $\mathrm{V}_{\mathrm{t}}$ value recorded during physical exercise was more prevalent among the subjects wearing woolen clothes, whereas in RR values among those wearing acrylic clothes.

The two parameters are controlled through slightly different mechanisms. The results obtained by Flandrois et al. [23] and Heistad et al. [24] suggest that the depth of breathing is controlled by noradrenaline (NA), mostly through the stimulation of the adrenergic nervous system, whereas the rate of breathing by adrenaline (A), through the activity of adrenal medulla. It is most likely that these 
two regulatory mechanisms (nervous and humoral) operate with a different intensity under particular conditions of physical exercise that are due to the specific clothing material of the outfit worn during the exercise. It seems that in the persons wearing $100 \%$ coarse wool clothing, the effects of NA and the sympathetic system dominate, whereas in those wearing $100 \%$ acrylic clothes, the effect of adrenal medulla and $\mathrm{A}$ is more pronounced.

The cardiovascular parameters (BP and HR) also differed significantly depending on the kind of clothing material. BP values were higher among subjects wearing woolen clothes. A statistically significant difference was noted before the exercise test, at half an hour of acclimatization in specific clothing (SBP1), and then one minute after the test (SBP2). The difference could be observed 7.5 and $10 \mathrm{~min}$ after the test (SBP3 and SBP4, respectively) but was no longer significant. The HR showed an opposite tendency; it was higher after acclimatization in the acrylic set of clothes. The differences observed after the effort were varying and not significant. The comparison of A and NA effects on the cardiovascular system revealed that A contributed to higher HR, whereas NA increased the BP values [25]. Therefore, it can be concluded that in the subjects wearing woolen clothing, the NA-ergic nervous mechanism predominates over the humoral A mechanism, while in the subjects wearing $100 \%$ acrylic clothes, a reverse reaction can be observed.

The effect of different clothing material on HR during physical effort has been investigated by Kwon et al. [26] who found higher HR values in individuals wearing synthetic (polyester) clothing than in those wearing cotton clothing, as well as by Gavin et al. [10] who, however, did not observe any effect of the clothing fabric on HR in persons examined during physical effort. The findings of our study confirm that HR is intensified by wearing clothes made of synthetic fabric.

The analysis of the cardiovascular parameters after physical effort and the rate of their returning to initial values revealed that in the subjects wearing woolen clothes, BP regained its initial values faster (after $7.5 \mathrm{~min}$ ) than in those wearing acrylic clothes (after $10 \mathrm{~min}$ ). HR remained higher for $10 \mathrm{~min}$ after the exercise test. These observations can be explained by the NA-A concept. In the persons wearing wool, the enhanced activity of the NA-ergic sympathetic system returns to normal values faster than that of the hormonal-A system from adrenal medulla. Adrenaline retention in blood accounts for the higher values of HR that maintain for $10 \mathrm{~min}$ after the test. Unfortunately, blood concentrations of NA and A were not considered in this study and thus there is no evidence that the NA-A hypothesis is correct.

The comparison of the psychomotor parameters (RT and CA) before and after physical effort in the subjects wearing different kind of clothing did not reveal any significant differences. Only the CFF value increased after physical effort in the subjects wearing woolen set, but no changes were observed among those wearing acrylic set, which suggests that the physical effort produced a favourable change in this parameter only in the former group. It is plausible that the physical exercise performed in acrylic clothes triggered a mechanism leading to decreased vascularization of the retina and worsened the conditions of its activity. This would stand in contrast to the generally shared view that moderate-intensity exercise enhances the activity of the central nervous system and exerts a positive effect on the cognitive performance [13]. Thus, the positive change that referred to CFF in the subjects wearing wool could have been expected in all the other psychomotor parameters under study.

It should be mentioned that the results of measurements in the subjects wearing acrylic clothes might be burdened with an error due to the fact that this measurement was performed as the second one during the experiment. Although the physical exercise that the subjects were to perform did not involve maximal effort, some of the subjects, although young and healthy, were tired as early as after the first trial. Thus, the physical effort performed in acrylic clothes (stage II of experiment) could have been more tiring for them. In our study, we decided to apply a uniform experimental model having always the same kind of material (wool) tested at stage I, after a preliminary series of experiments performed on two subjects which consisted in changing the order of the materials tested. This series did not show any influence of the sequence of testing materials 
on the study parameters. The woolen material was tested first as we thought that wearing it might be less burdensome for the thermoregulation process. We also expected it would be a better starting point for the second stage of the experiment performed in acrylic clothes.

The effect of the clothing material on human physiological parameters is usually investigated in the context of the thermal stress that may be associated with physical effort. In general, it is believed that the properties of clothing can considerably change the physiological conditions related to physical effort [7,27], but it has not always been possible to provide evidence that they affect the thermoregulatory mechanisms [10]. Zimniewska proved that even under static conditions, the temperature measured on the skin surface depended on the kind of clothing and was higher when the subjects worn polyester clothes than the linen ones [12,28].

The most significant effect of clothing on the human body lies in that it hinders the transmission of excess heat with water vapour from the skin surface, because clothing resists the passage of water vapour and thus decreases body heat loss by evaporative cooling. Moreover, clothing absorbs liquid sweat by capillary action, taking sweat away from the body surface, and reduces the cooling effect of evaporation. Natural fibres absorb sweat better than the man-made fibres. Therefore, the clothing made of natural fibres, which is capable of absorbing secreted sweat gradually, is more comfortable during physical effort.

However, this refers to a short-term physical effort. During a long-lasting effort, the absorption of sweat increases the mass of the clothing worn, which in turn produces an additional load for an individual performing exercise. Moreover, the evaporation process is hindered even more by wet clothing covering the body than by dry clothing. In view of the above, the thermoregulatory processes may be more impeded in persons wearing clothes made of natural fibers rather than synthetic materials. Apart from that, the electrostatic field formed by the charges accumulating on the surface of the synthetic clothing material [28], but not on the natural material, has influence on the physiological parameters in the persons wearing synthetic clothing.

\section{CONCLUSIONS}

1. The kind of clothing material, or in other words, whether the clothes are made of natural or man-made fibers, has influence on some physiological parameters in humans during the performance of physical effort. These parameters include the respiratory and cardiovascular but not psychomotor parameters.

2. The wellbeing of individuals wearing acrylic clothes, in relation to the physiological comfort, is worse after the physical effort, in contrast to the sensation they have after wearing woolen clothing.

3. The changes in physiological parameters recorded during the physical effort in relation to the kind of clothing material used in our experiment do not clearly demonstrate which type of material evokes lower or higher load.

4. The type of material for the clothes to be worn during a physical effort should be selected depending on the type, intensity and duration of the effort and taking into account the potential effects on human physiology.

\section{ACKNOWLEDGEMENTS}

The authors would like to thank Professor Dariusz Nowak for assistance in making arrangements for this research and Dr. Marek Kasielski for inspiration in statistics. This work was supported by the Medical University of Łódź, grant no. 503-8079-1 and by the Polish State Committee for Scientific Research, grant no. 3T08E 05127.

\section{REFERENCES}

1. Hatch KL, Markee NK, Maibach HI. Skin response to fabric a review of studies and assessment methods. Clothing Textiles Res J 1992;10(4):54-63.

2. Gwosdow AR, Stevens JC, Berlund LG, Stolwijk JA. Skin Friction and Fabric Sensation in Neutral and Warm Environments. Textile Res J 1986;56(9):574-80.

3. Rossi R. Interactions between protection and thermal comfort. In: Scott RA, editor. Textile for protection. Cambridge: Woodhead Publishing Limited; 2005. p. 233-60. 
4. Bartels VT. Physiological comfort of sportswear. In: Shishoo R, editor. Textiles in sport. Cambridge: Woodhead Publishing Limited; Textiles Series No. 45; 2005. p. 177-203.

5. Weil ED, Levchik S. Flame Retardants in Commercial Use or Development for Textiles. J Fire Sci 2008;26(3):243-281. DOI: $10.1177 / 0734904108089485$

6. Haase J. Standards for protective textiles. In: Scott RA, editor. Textile for protection. Cambridge: Woodhead Publishing Limited; Textiles Series No. 44; 2005. p. 233-60.

7. Gavin TP. Clothing and thermoregulation during exercise. Sports Med 2003;33(13):941-7.

8. Ha M, Tokura K, Yoden K. A comparison of skin temperatures and clothing microclimate during moderate intermittent exercise in the cold between one and two layers of cotton and polypropylene underwear. Int J Occup Saf Ergon 1998;4: 347-62.

9. Bakkevig MK, Nielsen R. The impact of activity level on sweat accumulation and thermal comfort using different underwear. Ergonomics 1995;38:926-39.

10. Gavin TP, Babington JP, Harms CA, Ardelt ME, Tanner DA, Stager JM. Clothing fabric does not affect thermoregulation during exercise in moderate heat. Med Sci Sports Exerc 2001;33(12):2124-30.

11. Nguyen MH, Tokura H. The different effects of black and white Vietnamese Aodai folk costumes on rectal temperature and heart rate in women walking intermittently in hot and sunny environment. Int J Occup Med Environ Health 2000;13(1): 27-38.

12. Zimniewska M, Huber J, Krucinska I, Torlińska T, Kozłowski R. The influence of clothes made from natural and synthetic fibres on the activity of the motor units in selected muscles in the forearm - Preliminary studies. Fibres and Textiles in Eastern Europe 2002;39(4):55-9.

13. Davranche K, Audiffren M. Facilitating effects of exercise on information processing. J Sports Sci 2004;22(5):419-28.

14. Pyska A, Zimniewska M, Witmanowski H. Natural and synthetic fibres: Influence on selected parameters of human health. Przew Lek 2005;8:79-83. [in Polish].

15. Wells EF, Bernstein GM, Scott BW, Bennett PJ, Mendelson JR. Critical flicker frequency responses in visual cortex. Exp Brain Res 2001;139(1):106-10.
16. Seitz AR, Nanez JE Sr, Holloway SR, Watanabe T. Perceptual learning of motion leads to faster flicker perception. PLoS ONE 2006;1(1):1-8. DOI 0.1371/journal.pone.0000028.

17. Teichner WH. Recent studies of simple reaction time. Psychol Bull 1954;51:128-49.

18. Zajdel R, Nowak D. Simple and complex reaction time measurement. A preliminary evaluation of new approach and diagnostic tool. Comput Biol Med 2007;37:1724-30.

19. Young GB, Pigott SE. Neurobiological basis of consciousness. Arch Neurol 1999;56:153-57.

20. Searight HR, Burke JM, Rottnek F. Adult ADHD: Evaluation and treatment in family medicine. Am Fam Physician 2000;62:2077-86.

21. Szczęsna-Kaczmarek A. Physiological characteristic of transition from an oxygen deficit to steady state during submaximal exercise: comparison of children and young adults. Annales Universitatis Mariae Curie-Skłodowska Lublin Sect D Medicina 2005;60 Suppl. 16(5):335-9 [in Polish].

22. Blusiewicz A., Zdanowicz R. Anaerobic threshold and state of maximal lactate balance - practical remarks. Sport Wyczyn 2002;1-2:445-6 [in Polish].

23. Flandrois R, Favier R, Pequignot JM. Role of adrenaline in gas exchange and respiratory control in the dog at rest and exercise. Respir Physiol 1977;30:291-303.

24. Heistad DD, Wheeler RC, Mark AL, Schmid PG, Abboud FM. Effects of adrenergic stimulation on ventilation in man. J Clin Invest 1972;51:1469-75.

25. Ganong WF. The Adrenal Medulla and Adrenal Cortex. In: Gowin-Kowalik J. Physiology. Warszawa: Wydawnictwo Lekarskie PZWL; 2007. p. 348-72 [in Polish].

26. Kwon A, Kato M, Kawamura H, Yanai Y, Tokura H. Physiological significance of hydrophilic and hydrophobic textile materials during intermittent exercise in humans under the influence of warm ambient temperature with and without wind. Eur J Appl Physiol Occup Physiol 1998;78(6):487-93.

27. Pascoe DD, Shanley LA, Smith EW. Clothing and exercise. I: Biophysics of heattransfer between the individual, clothing and environment. Sports Med 1994;18(1):38-54.

28. Zimniewska M, Michalak M, Krucińska I, Wiecek B. Electrostatical and thermal properties of the surface of clothing made from flax and polyester fibres. Fibres and Textiles in Eastern Europe 2003;41(2):55-7. 